\title{
The aftershock sequence of the north-west Kashmir earthquake of September 3, 1972
}

\author{
V. K. Srivastava (*) - R. K. S. Chouhan (*) - Rajiv Nigam (*)
}

Received on April 25th, 1975

\begin{abstract}
Summar. - This paper is an attempt to study the aftershock sequence of the Northwest Kashmir earthquake of September 3, 1972. $b$ value of the sequence is 1.59. The area of active strain zone is approximately $2.9 \cdot 10^{13} \mathrm{sq}$. cm. The total average strain, average elastic energy and average stress of the rock before slip are $3.3 \cdot 10^{-5}, 3.2 \mathrm{ergs} / \mathrm{cm}^{3}$ and 19.8 $\mathrm{kg} / \mathrm{cm}^{2}$.

The strain rebound curve of the sequence has been constructed which shows a dual type of recovery where the compressional elastic creep is followed by the shear creep recovery. The relaxation time of the sequence is about 0.7 day, showing the Kelvin body like behaviour of the upper mantle.
\end{abstract}

Riassunto. - Questo studio è un tentativo di indagine sulle repliche del terremoto del Kashmir nord-oceidentale del 3 settembre 1972. Il valore $b$ della sequenza è 1.59. L'area della zona di tensione attiva è approssimativamente $2.9 \cdot 10^{13} \mathrm{sq}, \mathrm{cm}$. La tensione media totale, l'energia media totale e lo stress medio della roccia prima dello slittamento sono $3.3 \cdot 10^{-5}$, $3.2 \mathrm{ergs} / \mathrm{cm}^{3}$ e $19.8 \mathrm{~kg} / \mathrm{cm}^{2}$.

La curva di risposta della tensione della sequenza che è stata costruita mostra un doppio tipo di ripresa in cui la deformazione elastica compressionale è seguita dalla ripresa di deformazione trasversale. Il tempo di rilassamento della sequenza è cirea 0.7 giorni, mostrando come il corpo di Kelvin si comporti similmente al mantello superiore.

(*) Department of Applied Geophysics, Indian School of Mines, Dhanbad - 826004, India. 


\section{1 - INTRODUCTION}

The relocated epicenter of the $\mathrm{N}-\mathrm{WT}$ Kashmir Earthquake which occurred on Sept. 3,1972 at $16^{\mathrm{h}} 48^{\mathrm{m}} 31.64^{\mathrm{s}}$ GMT was at $35.95^{\circ} \mathrm{N}$, $73.29 \circ \mathrm{F}$. The unifier magnitude of this shock was 6.2 and focal depth was $64 \mathrm{~km}$. The aftershock which followed the main shock were distributerl over an area extending from latitude $35.5^{\circ} \mathrm{N}$ to $36.5^{\circ} \mathrm{N}$ and longitude $73 \mathrm{oE}$ to $74 \mathrm{oE}$ respectively. All the rata are recalculated with the help of computer. The unified magnitudes of the aftershocks used in the present sturly ranged from 4.0 to 5.8 .

\section{2 - SeIsmicity OF N-IV KASILIIR RTGION}

Kashmir region is very much seismically active due to syntaxial structure bend of the Himalayas. The epicenter of earthquakes are considered to coineide with the Main Boundary faults and any movement along this fault may cause earthquake.

Fin. 1 shows the spatial distribution of the aftershocks of the September 3, 1972 with dislocation line and isostatic gravity anomaly maj. The epicenters of the aftershocks of higher magnitude in the range of 4 to 5.9 are clustered in and around the main shock. A little north to main shock, the epicenters of the aftershocks are of magnitude below 4.0. But the ristribution pattern of epicenters does not show any regular trend. However, the map clearly shows that the epicenters of the aftershocks can be correlates with the dislocation line, presumably, the main boundary fault of the region, and they are concentrated in positive isostatic anomaly region. This association of positive anomaly shows that the area is in isostatically over compensated. Thus this may be a cause of shallow shocks in this region, Antonio Marussi (11).

\section{3 - Frequexcy-MagNitude hNitysis.}

A well known relation between cumulative frequency of shocks and its magnitude is given by Gutenberor and Richter $\left({ }^{9}\right)$ in the form

$$
\mathrm{J}_{\mathrm{og}_{10}} N=a-b M
$$




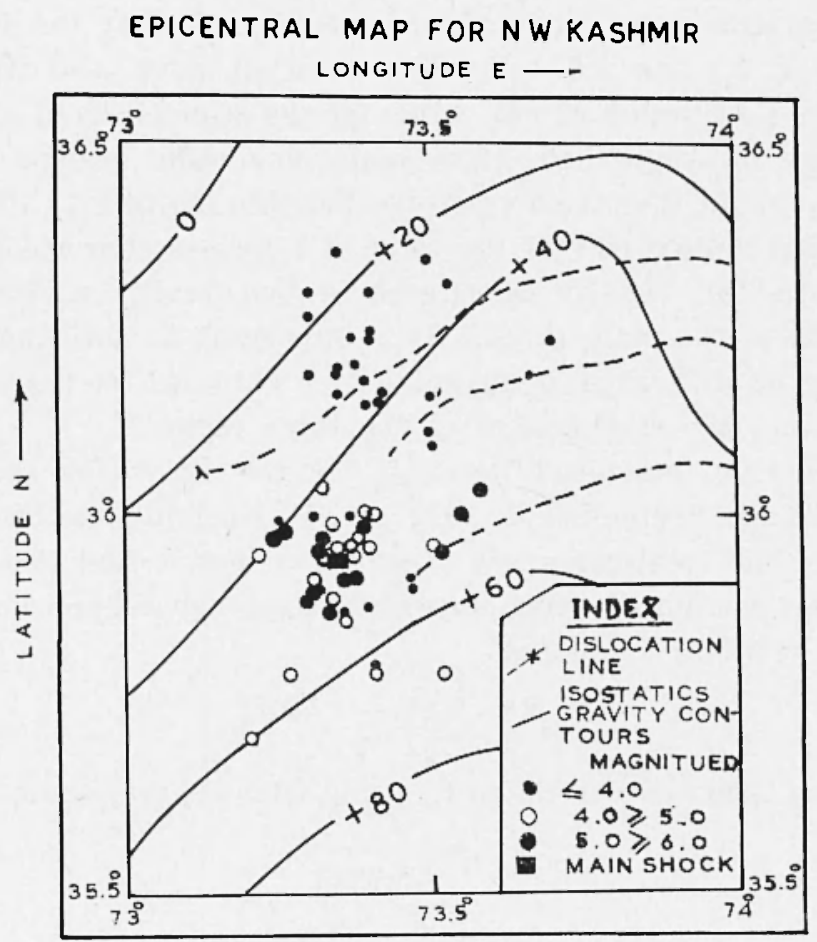

Figr. I - Epicentral map of NW Kashmir of September 3, 1972 earthqualie.

The constant $b$ of this equation is related to the tectonic structure of the seismic region. Mogi (13) showerl experimentally that this constant $b$ depends on the homogeneity of the material in the seismic region and on the distribution of applied stress. The value of $b$ increases as the degree of heterogeneity increases and as the degree of symmetry of applied stress decreases. However, Scholy (16) has shown that value of $b$ depends upon the state of stress rather that the heterogeneity of the material in a resion.

Gutenberg and Richter $\left({ }^{9}\right)$ have studied in detail the FrequencyMagnitude relation for shallow, intermediate and (leep focus earthquakes. This relation has been also used by Chouhan (5) to study regional charateristies.

Utsu $\left({ }^{19}\right)$, Suychiro $\left({ }^{1-}\right)$, Chouan (6) ete., have shown that the above relation is applicable to the aftershocks sequences also. Utín (19) has summarised the magnitude distribution of the aftershocks in and 
near Japan and some other regions. He found that the value of $b$ lies between 0.5 and 1.5. Chouhan et al ( ${ }^{7}$ ) have also studied the magnitude distribution of " $b$ " value for the aftershocks of the Assam Earthquake of $\Lambda$ ugust 15, 1950, and some other regions of India. They have found that the $b$ value lies between 0.5 to 1.1. Papazachos et al. $\left({ }^{14}\right)$ have observed that the value of $b$ decreases for the aftershock sequence in the vicinity of Greece systematically with increasing focal depth of the main shock. It is important to note that there is practically no difference in the value of $b$ obtained for the aftershock sequence and the earthquakes of the same region.

$\Lambda$ frequency-magnitude analysis for the aftershock sequence of the earthquake September 3, 1972 of NW-Kashmir has been carried out here. The resulting graph is shown in Fig. 2 and the values of $a$ and $b$ are computed using univariate least square procedure. The following relation is obtained

$$
\log N=8.97-1.59 M
$$

$b$ value has been also calculated by using Utsu (21) maximum likelihood methor,

$$
b=\frac{0.4343}{\left(\bar{M}-M_{\mathrm{min}}\right)}
$$

where $\bar{M}$ is the average magnitude for the series and $M_{\mathrm{m} \text { in }}$ is the minimum magnitude. The $b$ value is found to be 1.5 by this method.

The value of $b$ for this sequence is rather large and this may be attributed due to low stress level in the region, Scholz (16). Further this high value of $b$ is also due to the small magnitude range taken here. Papazachos (15) has shown that the reliable $b$ values are determined only if this range is large enough for seismic sequence.

\section{4 - STRAIX RELEASE IN THE AFTERSHOCK SEQUENCE}

To study the elastic energy release behaviour in this sequence a most popular method of Benioff $\left(^{2}\right)$ has been applied. He has shown that the potential energy $J_{p}$ of a volume of rock $V$, possessing a coefficient of shear $\mu$, strained an average amount $\varepsilon$ immediately before the earthquake is given by

$$
J_{p}=\mu V \varepsilon^{2} / 2
$$




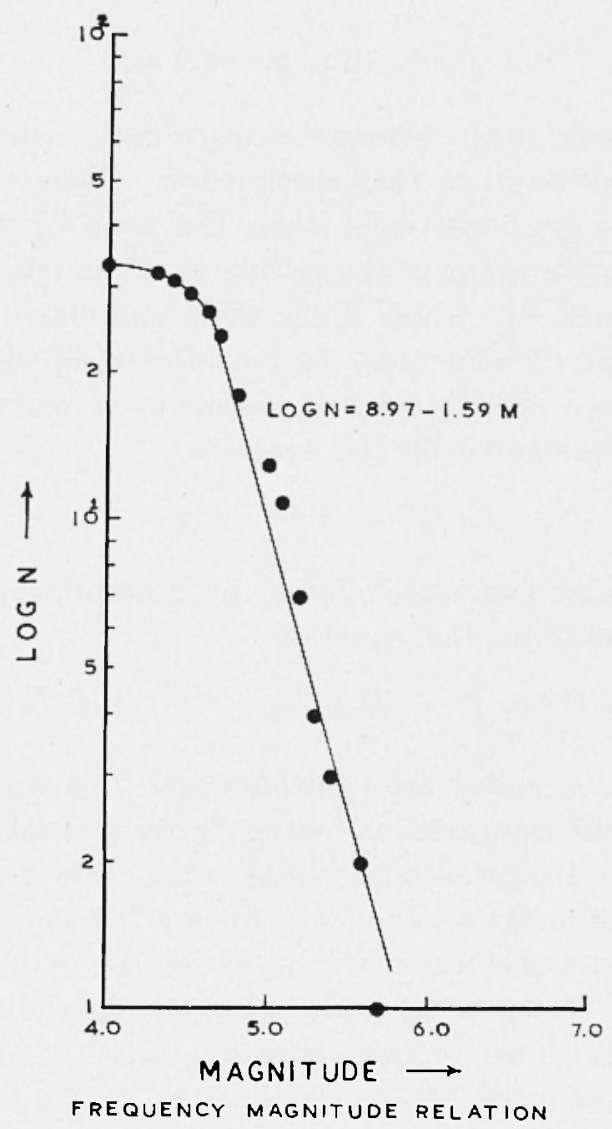

Fig. 2 - Frequency-Magnitude relation curve for September 3, 1972 earthquake.

and the energy of released seismic wave $(J)$ is

$$
J=\eta \mu V \varepsilon^{2} / 2
$$

where $\eta$ is the fraction of energy releaser as seismic waves, the rest being consumerl in heat and displacement work.

If $\eta$ is one, then entire potential energy is released as seismic waves. Thus for equation [5] strain $\varepsilon$ can be calculated if seismic energy $J$, the volume $V$ and the coefficient of shear $\mu$ are known.

For calculating the energy, Gutenberg Richter's (10) formula is used $\log J=5.8+2.4 m$ or

$$
\log J^{1 / 2}=2.9+1.2 m
$$




$$
\text { or } J^{1 / 2}=10(2.9+1.2 m)
$$

Fig. 3 is the elastic strain rebound characteristies curve for the aftershock sequence of Sejt. 3,1972 earthquake. There the time $t$ of the aftershocks have been reckoned from the time of the main shock. Then the cumulative values of the calculated strain rebounds $S-\Sigma_{i} J^{1 / 2}$ are plotted against " $t$ " which gives the accumulated strain rebound (times a constant $C$ ) increments of the aftershock sequence.

This sequence consists of two segments of recovery, one linear which can be represented by the equation

$$
\Sigma_{i} J^{1 / 2}=A+B \log t
$$

$A$ and $B$ being constant followed by a non-linear segment which can be represented by the equation

$$
\Sigma_{i} J^{1 / 2}=A^{\prime}+B^{\prime}\left(1-e^{-\alpha t^{1 / 2}}\right)+C T^{\beta}
$$

where $A^{\prime}, B^{\prime}, \alpha, C$ and $\beta$ are constants and $T$ is wave period. This is a case where the compressional creep recovery is followed by a shear creep recovery. Compressional phase commences immerliately after the main shock and the shear phase starts a few hours after the main shock. These interpretations are based on the empirical results obtained by Griggs $\left(^{8}\right)$ for rocks under compression and those of Michelson's (12) for rocks under torsional stresses. Accordingly compressional creep recovery is caused by the elastic after working of the compressional stresses and the shear creep recovery also results by the elastic after-working of the shearing stress. The release of strain in two phases, compressional and shear has also been noticed by Benioff. $\left.{ }^{3}\right)$ Bath and Duda (1) and Chouhan (6).

The character of the strain rebound increments with time in Fig. 3 strongly resembles with the strain release behaviour of Kelvin Solid. The maximum $S$ reached in Fig. 3 corresponds to the unstrained portion of the Kelvin body, the zero value of $S$ to the loaded position. Eventually the curve is not expected to come to a complete levelling off, as in addition to the strain release, it must be expected that a constant build up of stress oceurs at a slow rate which, presumably, never comes to stop. Thus after a few years one would expect the same pattern to repeat itself. Thus the present behaviour of strain release can be explained in terms of elastio afterworking of Kelvin solid. 


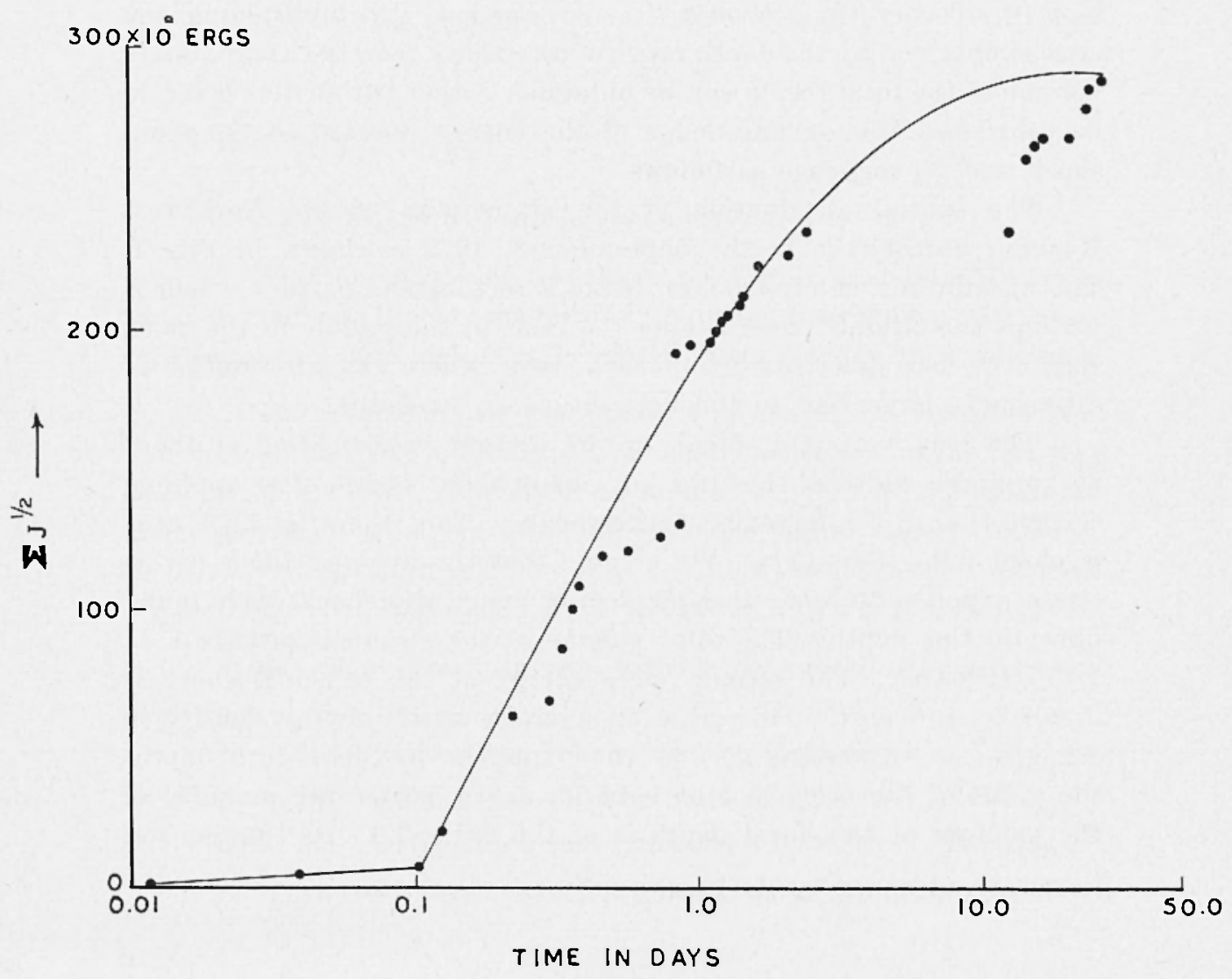

Fig. 3 - Accumulated elastic strain rebound increments (time c) of the Sept. 3, 1972 earthquake of NW Kashmir.

The time in which the strain drops to $1 / e$ times the initial value, called relaxation time, in this case is about 0.7 day. This relaxation time is also equal to the ratio $\nu / \mu$, where $\mu$ is the coefficient of rigidity and $v$ is the coefficient of viscosity.

$\overline{5}$ - STRAIN CHARACTERISTICS OF THE FOCAL, REGTOX

Wilson (22) plotted aftershock epicentres to delimit the area of the strained zone involved in the Nevada earthquake of 1936. Since 
then the procedure has been utilised by many workers such as Benioff' ${ }^{(3)}$, Tocher $\left({ }^{18}\right)$, Chouhan (5) etc. Further, by multiplying the area so obtained by the depth range of aftershock foci, the approximate volume of the focal region can be obtained. Other parameters can also be calculater from a knowlerlge of the energy released in the nain shock and its sequence as follows.

The spatial distribution of the aftershocks of the Northwest Kashmir earthquake of the September 3,1972 is shown in Fig. 1. The distribution of aftershocks define a rectangular pattern which is perhaps the strained zone having the fault in the midlle of the zone. Benioff ( $\left.{ }^{4}\right)$ has described many such cases where the distribution of aftershocks have lead to the delineation of the faults.

The length of fanlt break in the present investigation is about $66 \mathrm{~km}$ and a width of the strained zone is about $44 \mathrm{~km}$ after applying a correction of the location of aftershocks. Thus the aftershock area is about $2.9 \cdot 10^{13} \mathrm{sq} . \mathrm{cm}$. We assume that the average depth of the strain region is $50 \mathrm{kms}$, since the foci of many aftershocks were found down to this depth. The total volume of the strained rocks is $V$ $1.45 \cdot 10^{20} \mathrm{~cm}^{3}$. The seismic wave energy of the principal shock is $J=4.7 \cdot 10^{20}$ ergs. This gives an average elastic energy density of $3.2 \mathrm{ergs} / \mathrm{cm}^{3}$. Assuming $\mu=6 \cdot 10^{11}$ dynes $/ \mathrm{cm}^{2}$ at this is focal depths the value of the coefficient of viscosity $(v)$ or better the mobility of the merlium at this focal depth is of the order $3.6 \cdot 10^{17} \mathrm{gm} / \mathrm{cm} / \mathrm{sec}$.

From formula [5] of section 4 i.e.,

$$
\varepsilon^{2}=2 J / \mu \nu
$$

assuming $\eta=1$ and putting $\mu=6 \cdot 10^{11}$ lynes $/ \mathrm{cm}^{2}$. The elastic strain preceeding the principal earthquake is thus $\varepsilon=3.3 \cdot 10^{-5}$. The total strain release upto the end of the sequence is proportional to $\sum J^{1 / 2}=2.86 \cdot 10^{10}$. For principal earthquake corresponding quantity is $J^{1 / 2}=2.1 \cdot 10^{11}$.

The elastic stress just before the fracture is roughly

$$
\begin{gathered}
\sigma=\varepsilon \mu=6 \cdot 10^{11} \cdot 3.3 \cdot 10^{-5} \text { dynes } / \mathrm{cm}^{2}=19.8 \cdot 10^{6} \text { dynes } / \mathrm{cm}^{2}= \\
=19.8 \mathrm{~kg} / \mathrm{cm}^{2} .
\end{gathered}
$$

If " $l$ " = wirlth of the aftershock region, the total relative slip " $x$ " during the principal shock is $x=\varepsilon \cdot l=3.3 \cdot 10^{-5} \cdot 4.4 \cdot 10^{\text {fi }} \mathrm{cm}$ $=145.2 \mathrm{~cm}=1.45$ meter. 
This displacement is a rough approximation since $\varepsilon$ as used here represents the shear strain only very approximately.

\section{6 - Conclusion.}

The study brings out the following results:

1) The magnitude of the aftershocks are distributed according to the Gutenberg-Richter magnitude frequency relationship with value of $b$ equal to 1.59 which is rather large in comparison to main shock.

2) The release of strain occurs in two phases, the compressional and shear. The remarkable feature of this sequence is that the recovery is almost shear creep recovery with a small amount of compressional creep recovery. The relaxation time for the shear phase is found to be 0.7 days. Assuming rigidity $\mu=6 \cdot 10^{11}$ dynes $/ \mathrm{cm}^{2}$, the coefficient of viscosity, $v$, in the region is of the order of $3.6 \cdot 10^{17} \mathrm{gm} / \mathrm{cm} / \mathrm{sec}$.

3) a) - The aftershock area is $2.9 \cdot 10^{13} \mathrm{~cm}^{2}$ and the aftershock volume is $1.45 \cdot 10^{20} \mathrm{~cm}^{3}$.

b) - The elastic strain just before the main shock is $3.3 \cdot 10^{-\bar{a}}$.

c) - The strain release by the main shock is $2.1 \cdot 10^{11}$.

(i) - The elastic stress just before the fracture is $19.8 \mathrm{~kg} / \mathrm{cm}^{2}$.

e) - The displacement along the fanlt plane is 1.45 meters.

\section{ACKNOWLEDGEMENT}

The authors are grateful to Profs. J. Singh and R. K. Yerma for discussions from time to time and for providing all the facilities to carry out the present work. Junior author acknowledges the financial support from the C.S.T.R. Scheme in the form of Junior Research Feilowship.

\section{REFERENCES}

(1) Bגті M., DUDa S. .., 1964. - Earthqualie volume, faull plane area, seismic energy, strain deformation and relalion quantities. "Annali di Geofisica", 17, pr. 353-368. 
$\left.{ }^{2}\right)$ Bexiof H., 1949. - Seismic evidence for the jaull origin of Oceanic depth, "Bull. Geol. Soc. An.", 60.

$\left({ }^{3}\right)$ BexiofF II., 1955. - Mechanism and strain characteristes of the while wolf jaull as indicated by the aflershock sequence. "Calf. Dir. Mines. Bull.", 177, p. 199.

(4) BExıFF H., 1962. - Movement on major transcurrent jaulls. "Continental drift by S. K. Runcorn Chapter 4, p. 103. Academic Press.

$\left(^{5}\right)$ Cinounax R. K. S., 1968. - Seismicity of India and some recent aflershock sequences. Pl.. D). thesis, University of Roorkee.

$\left({ }^{6}\right)$ Cimoumax R. K. S., Gaur V. K. and Ratior II. S., 1970. - Aflershock scquence of the Solomon Istand Earthqualie of June 15, 1966. "Pure and Applied Geophysies", 162.

${ }^{7}$ ) Choumax R. K. S., Srivastava Y. K., 1970. - Global variation of b in the Gutenberg Richter's relation, Log $N=a-b M$ with depth. "Pure and Applied Geophysies", 82, pp. 124-132.

$\left({ }^{8}\right)$ Grigers D., 1939. - Creep of rocks. "Jour. Geol.", 47.

$\left({ }^{9}\right)$ Gutenberg; B., Riciter C. F., 1954. - Seismicity of the Earth and Associated phenomena. "P'rinceton I'niversity Press".

$\left({ }^{10}\right)$ Gutenberg; 13., Riciter C. F., 1956. - Magnitude and energy of earthquakes. "Annali di Geofisica", IX.

(11) Marussi A., 1964. - Geophysics of the Karahorum. Seientifie Report, "Geoplıysies II", I, Istituto di Geologia, Università di Milano (Italy).

(12) Micimson A. A., 1920. - Elastic Viscous fow, Part II. "Jour. Geol.", 28.

(13) Mogi K., 1962 b. - Study of elastic shocts cansed by the fracture heterogeneous materials and its relation to earthquate phenomena. "Bull. Earth. Res. Inst.", 40, pp. 125-174.

(14) Papazacios 13., Melibasis N., Jiapis N., Moumoulimis G., Purcaru G., 1967. - 1jlershock sequences of some larger earthquales in the region of Greece. "Annali di Geofisiea", Rome, XX, pp. 1-93.

(15) Papazacios B. C., 1974. - Dependence of the seismic parameter b on the magnilude range. "Pure and Applied Geophysics", 112, pp. 1059-1065.

${ }^{(16)}$ Scnotz C. M., 1968. - The Frequency-Magnitude Relation of Microfracturing in Roch and its Relation in to Earthquakes. "Bull. Seism. Soc. Am.", 58, pp. 399-415.

${ }^{(17)}$ Survitro S., 1964. - An example of fore and aftershock sequences and difference in the relation between magnitude and frequency of occurrence between two sequenees. C.S. Japan conference on Earthquake prediction, 53.

${ }^{(18)}$ Tocmen Dos, 1959. - Seismographie resulls from the $195 \pi$ San Francisco Earthquake. "Special Report, Calif. I)iv. Mines", 61.

$\left({ }^{19}\right)$ UTsu T., 1961. - A slatistieal shudy on the occurrence of aftershochs. "Geophysies Mag.", 30, pp. 521-605. 
(20) UTsu T., 1964. - Characteristics of aftershocks in space, time and magnitude. L.S. Japan conference on earthquake prediction, 59.

${ }^{21}$ ) UTsu T., 1965. - A method of determining the value of b in a formula Log $N=a-b$ b showing the magnitude frequency relation earthquakes (in. Japanese with English abstract). "Geophys. Bull.", IIokkaido Univ., 13, pp. 99-104.

$\left.{ }^{(22}\right)$ Wilsox J. T., 1936. - Foreshocks and ajtershocks of the Nevada earthqualie of December 20, 1932 and the Park field earthquake of June $\tilde{r}$, 1934. "Bull. Scis. Soc. Am.", 26, p. 189. 